\title{
Factores que condicionan la autotraducción. El caso de Los misterios del Plata, de Juana Manso'
}

\author{
Ana Eugenia Vázquez \\ geu.vazquez@gmail.com \\ Universidad de Buenos Aires y Consejo Nacional de Investigaciones \\ Científicas y Técnicas, Argentina
}

\section{Resumen}

Al hablar del "caso" de Los misterios del Plata y no del "ejemplo", queremos señalar que los factores que condicionan la autotraducción no son aplicables universalmente, a pesar de que la decisión sobre las opciones de traducción parezca estar en manos de la traductora. Por eso, estudiamos diversos factores supraindividuales que restringen la autonomía del traductor-autor, tanto glotopolíticos como sociales, en el caso de la autotraducción que realizó Juana Manso de la novela por entregas Os Mysterios del Plata, publicada en portugués en su exilio brasileño en 1852 y que, regresada del exilio, tradujo al español y publicó a partir de 1867 bajo el título de Guerras civiles en el Río de la Plata. Una mujer heroica. En el nuevo contexto político, la escritura debía tener una función diferente. La novela en castellano era también bastante más breve, puesto que suprimía explicaciones innecesarias para el público argentino. Se acentuaba la intención didáctica y el protagonismo se desplazaba al problema de la mujer. Para rastrear estas diferencias, nos basamos en la contrastación entre original y traducción. En definitiva, queremos mostrar cómo la ubicación del autotraductor frente al par de lenguas y las circunstancias políticas y sociales concretas condicionan inevitablemente la práctica de la autotraducción.

Palabras clave: autotraducción; glotopolítica; Los misterios del Plata (Juana Manso); novela gótica; novela histórica nacional; romanticismo.

\section{Factors Conditioning Self-Translation. The Case of Juana Manso's Los misterios del Plata}

\begin{abstract}
By speaking of the "case" of Los misterios del Plata and not of the "example", we wish to point out that the factors that condition self-translation are not universally applicable, even though the decision on translation options seems to be in the hands of the translator. That is why we study various supra-individual factors that restrict the autonomy of the translator-author, both glottopolitical and social in the case of Juana Manso's self-translation of the serialised novel Os Mysterios del Plata, published in Por-
\end{abstract}

1 El presente trabajo se enmarca en el Proyecto de Investigación Científica y Tecnológica (PICT) 2018-2022,

"El lugar de las mujeres en el campo editorial: posiciones, trayectorias y prácticas editoriales en Argentina". Quiero agradecer especialmente al profesor Roberto Bein, cuyo apoyo y reflexiones son disparadores de este artículo. 
tuguese in her Brazilian exile in 1852 and which, on her return from exile, she translated into Spanish and published from 1867 onwards under the title Guerras civiles en el Río de la Plata. Una mujer heroica. In the new political context, writing was to have a different function. The novel in Spanish was also much shorter, as it did away with unnecessary explanations for the Argentinian public. The didactic intention was accentuated and the focus shifted to the problem of women. In order to trace these differences, we rely on the - in this case, inevitable - contrast between the original and the translation. In short, we want to show how the location of the self-translator in relation to the language pair and the specific political and social circumstances inevitably condition the practice of self-translation.

Keywords: self-translation as rewriting; political context; change of addressee; female protagonism.

Facteurs qui conditionnent l'auto-traduction. Le cas de Los misterios del Plata, de Juana Manso

\section{Résumé}

En parlant du « cas » de Los misterios del Plata et non de l'« exemple », nous souhaitons souligner que les facteurs qui conditionnent l'autotraduction ne sont pas universellement applicables, même si la décision sur les options de traduction semble être entre les mains de la traductrice. C'est pourquoi nous étudions divers facteurs supra-individuels, à la fois glottopolitiques et sociaux, qui limitent l'autonomie de Juana Manso dans son autotraduction du roman-feuilleton Os Mysterios del Plata, publié en portugais pendant son exil brésilien en 1852 et que, à son retour d'exil, elle a traduit en espagnol et publié à partir de 1867 sous le titre Guerras civiles en el Río de la Plata. Una mujer heroica. Dans le nouveau contexte politique, l'écriture devait avoir une fonction différente. Le roman en espagnol était également beaucoup plus court, car il supprimait les explications inutiles pour le public argentin. L'intention didactique a été accentuée et l'accent a été mis sur le problème des femmes. Afin de retracer ces différences, nous nous appuyons sur le contraste - dans ce cas, inévitable - entre l'original et la traduction. En bref, nous voulons montrer comment la situation de l'autotraductrice par rapport à la paire de langues et les circonstances politiques et sociales spécifiques conditionnent inévitablement la pratique de l'autotraduction.

Mots clés : autotraduction comme réécriture ; contexte politique ; changement de destinataire ; protagonisme féminin. 


\section{Introducción}

Los trabajos que en los últimos veinte años han abordado de manera creciente la autotraducción pueden dividirse en dos vertientes: aquellos que la consideran una oportunidad privilegiada para el desarrollo de la creatividad autoral (AUTOTRAD, 2007; López LópezGay, 2008; Sperti, 2017; Tanqueiro, 2002) y otros que prefieren estudiar cada caso concreto en sus condiciones sociohistóricas, ya sea desde el análisis del discurso, la sociología de los campos, la glotopolítica o las perspectivas que combinan estudios literarios e historia cultural (Dasilva, 2015, 2018; Grutman, 2009; Spoturno, 2015, 2019). Por tanto, hablar del "caso" de Los misterios del Plata, y no del "ejemplo", muestra por dónde se encaminan nuestras reflexiones: creemos que los factores que condicionan la autotraducción no son aplicables universalmente, lo cual no significa que no podamos señalar ciertas características que tienen muchas de ellas.

Para indagar dicha complejidad, analizamos el caso de las autotraducción de Os Mysterios del Plata [sic], ${ }^{2}$ que Juana Manso realizó en 1867. Para ello, hacemos una revisión histórica de la autotraducción y desplegamos las características que se deben distinguir en la autotraducción de Manso. Con este fin, situamos las condiciones de publicación de cada texto, para, luego, proceder a un cotejo de ambas versiones y delinear ciertas decisiones traductivas que permiten explicar las transformaciones operadas en la autotraducción.

\section{Romanticismo y autotraducción}

Al presente, no hay estudios que hayan abordado la autotraducción en el período de publicación del texto estudiado. La historia

2 La hibridez del título de la novela, entre el español, el portugués y el francés, responde tanto a la inestabilidad ortográfica del siglo XIX como a la posición entre culturas que asume Manso en O Jornal das Senhoras. de la traducción en el siglo XIX argentino es, en su mayoría, un área vacante sobre la que, sin embargo, existen trabajos precursores, los cuales delinearon problemáticas y ejes de análisis centrales (Fernández Speier, 2019; Pagni, 2013; Willson, 2008).

Por el contrario, desde principios de siglo, la autotraducción ocupa un lugar cada vez más importante dentro de los estudios de traducción. Algunas de estas teorizaciones buscan destacar los rasgos que distinguen la autotraducción de las demás. Por ejemplo, en su abarcadora tesis doctoral, Autotradução: Autoridade, privilégio e modelo, Helena Tanqueiro (2002, p. 56) explica que el autotraductor gana un estatus privilegiado proveniente del dominio que tiene sobre la traslación y los sentidos posibles de su propio texto. Otros casos se centran en la autotraducción como reformulación del proyecto subjetivo del autor, en pos de su consagración internacional, en especial en contextos de exilio. $\mathrm{Al}$ igual que lo que ocurre con Manso, la paratextualidad constituye para estos trabajos una zona privilegiada de negociación de los proyectos autorales y sus ethos (cf. Spoturno, 2019).

Al respecto, los estudios de traducción, en especial en sus perspectivas sociohistóricas, establecieron que las transformaciones son inevitables: en la traducción no solo se produce una recodificación lingüística, sino además una literaria e institucional (Brisset, 1990). De este modo, las condiciones de publicación (que en el siglo xIx argentino podían incluir la asociación con un impresor o editor oficial, así como con un periódico polémico y su coyunturalismo) imponen condicionantes decisivos a la traducción, tanto a su práctica como al producto de ella. Al respecto, no podemos omitir las exigencias editoriales en cuanto a variedad, peritextos, presentación gráfica, etc. Estas exigencias varían de un proyecto editorial a otro, y pueden ser menos fuertes cuando el traductor goza de renombre; posiblemente también se le permita mayor libertad. 
En cuanto a las "normas" formuladas por Gideon Toury (2005, pp. 94-107), relativas a la elección de los tipos de texto a traducirse, a la matriz del texto (distribución del material lingüístico), a la segmentación o a la redistribución textuales, a las omisiones, etc., no son distintas para el autotraductor que para los demás traductores.

En efecto, para entender la autotraducción de Manso, resulta significativo reponer algunas de las marcas constitutivas de la traducción en el siglo XIX argentino. Como señala Patricia Willson (2008), los traductores decimonónicos fueron letrados pertenecientes a la élite patricia liberal, es decir, transculturadores que adaptaron imaginarios y modelos culturales europeos a la realidad americana, de acuerdo con su proyecto político local.

Durante la primera mitad del siglo, a causa del endeble estatus de la edición argentina, los traductores debieron publicar sus traducciones en la prensa, soporte más accesible y democrático que el libro. Para ello, se nuclearon en proyectos periodísticos colectivos que abandonaron el latín, la referencia cultural todavía hegemónica de los letrados locales unitarios y clásicos, y adoptaron el francés, lengua de la Ilustración, la prensa y la novela. Esta decisión, vinculada a los modos de traducir, se complementa con numerosos artículos que criticaron y ridiculizaron las decisiones de la Real Academia Española, es decir, que lucharon contra la dominación simbólica de la norma peninsular sobre América.

Esta operación lingüística, como evidencia Pascale Casanova (2021), no es inocente, sino que busca modernizar la lengua española, despojándola de las "pesadas" marcas del español académico y acercándola a la prosa amena y atractiva de los periodistas y novelistas franceses, que cautivaban a los públicos de todo el mundo (Goldgel, 2013).

Desde estas publicaciones, los románticos alentaron un proyecto de reforma del español americano y la constitución de la literatura nacional que buscaba, ante todo, romper con la rémora de la tradición colonial (Donghi, 2005). Así, por ejemplo, un artículo de Juan Bautista Alberdi, publicado en La Moda en 1838, sostenía respecto del uso de los galicismos:

El que la voz album no sea castellana es para nosotros que ni somos ni queremos ser puristas, objeción de poquísima importancia [...]. Nosotros, queriendo ser más castellanos que los mismos castellanos, más puristas y más netos que los mismos españoles, más españoles que los españoles, igraciosa anomalía! (2011, p. 128).

Esta irreverencia frente al academicismo lingüístico español quedó cristalizada también en la reforma ortográfica elaborada por Domingo Faustino Sarmiento en Chile hacia mediados de siglo. Elvira Narvaja de Arnoux (2008) analiza agudamente el campo semántico bélico y la acentuación de "los aspectos jacobinos" (p. 182) que permean la defensa que el sanjuanino hace de su propuesta en la prensa periódica de la época. Inspirados en Jean-Jacques Rousseau, tanto Sarmiento como Alberdi se propusieron "revolucionar la lengua" (Narvaja de Arnoux, 2008, p. 182) para nacionalizar la cultura y, especialmente, la literatura.

El análisis de la autotraducción de Manso impone, además, abarcar cuestiones vinculadas a los cruces entre estudios de traducción y estudios de género, dado que muchas de sus decisiones importadoras, aunque, como veremos, se inscriben en el ideario de los románticos porteños, se deben a su condición de mujer letrada e independiente en un campo decimonónico que recluía las feminidades al matrimonio, el hogar y el cuidado de los hijos (Batticuore, 2005).

Aunque no profundizaremos este aspecto en el presente trabajo, Juana Manso fue una ferviente defensora de la educación y los derechos cívicos femeninos. Como ya han analizado Graciela Batticuore (2005) y Liliana Zucotti (1994, 1995), el proyecto novelístico 
de Manso se encuentra, por entero, atravesado por su ideario protofeminista, ya sea en la elección de heroínas femeninas activas y resueltas (como la que protagoniza Os Mysterios del Plata, en clara oposición a las protagonistas pasivas y sentimentales del gótico), o en sus estrategias de construcción de una "autoría exhibida" (Batticuore, 2005), siempre vinculadas a la figura de la pedagoga, la publicista y la intérprete crítica de la realidad americana.

Para Carvalho et al. (2020), en el caso de Manso:

Se trata, por lo tanto, incluso antes de la concepción de la idea y del término de una pedagogía decolonial, de un caso práctico y efectivo de mediación cultural, dado que Manso "tradujo" Argentina para las lectoras brasileñas y Brasil para las lectoras argentinas. Al publicar ambas novelas de denuncia social no en el país correspondiente al tema denunciado; sino a través de los periódicos que crea, es posible percibir la utilización del mundo de la prensa como mediador de esos cambios interculturales (p. 219).

En el presente trabajo avanzamos sobre algunas de estas hipótesis a partir del cotejo de las estrategias textuales desplegadas en la autotraducción, especialmente en la dimensión glotopolítica en juego y en la inclusión y la organización de paratextos. Describimos las transformaciones operadas sobre el texto fuente y luego las explicamos a partir de la posición de Manso en los respectivos campos culturales americanos y del estatus de las publicaciones periódicas en las que incluyó sus novelas.

\section{Glotopolítica y autotraducción}

La práctica de la autotraducción, aunque se remonta a la Antigüedad clásica, se intensificó con el nacimiento de los Estados centralizados y el desplazamiento del latín como lengua dominante a las lenguas vernáculas, que se habían formado unos siglos antes, pero que a partir del siglo XVI comenzaron a adquirir funciones científicas, religiosas y gubernativas.
Este fenómeno explica por qué se multiplicaron las autotraducciones del latín a las lenguas nacionales (cf. p. ej. López López-Gay, 2008) a partir del siglo XVII.

Como señala Casanova (2021, p. 18), por lo común se asume que las traducciones son inferiores al original y que la traducción acarrea una pérdida de valor, salvo que se realice a la que en cada época sea la lengua mundial: primero, el latín, luego el francés, con alguna presencia del alemán y el italiano; hoy día, el inglés. El prestigio de esa lengua es ciertamente una representación no basada en características lingüísticas, como una presunta mayor riqueza de vocabulario o gramatical, sino en creencias que están en consonancia con representaciones sociales de sus hablantes; pero, a su vez, le otorga prestigio a la traducción a esa lengua. Casanova (2021, pp. 93 y ss.) incluso explica que fue la consolidación del francés como lengua mundial la que permitió las "bellas infieles", las traducciones con fuertes cambios respecto del original.

A partir del siglo XIX, con la constitución de los Estados nacionales, la ampliación del público lector y la emergencia a escala transnacional de un mercado editorial, se consolida tanto en Europa como en América la concepción herderiana que plantea la lengua y la literatura como las portadoras privilegiadas de las supuestas especificidades culturales de cada nación. Con el nuevo valor que adquiere la "originalidad" en el imaginario cosmopolita francés de mediados del siglo XIX, emerge una nueva norma de traducción, la de la traducción literal, que ahora hace de Francia el centro de la modernidad (Casanova, 2021, p. 119).

Desde una óptica glotopolítica, debemos analizar la situación del autotraductor, al igual que la del traductor, en sus relaciones de producción: quién encarga la traducción, quiénes la leerán, cuál es el panorama lingüístico de la sociedad receptora, cuáles son los medios de difusión de la letra escrita, qué ideologías lingüísticas dominantes y qué re- 
presentaciones acerca de cómo debe ser una traducción adecuada y aceptable comparte el traductor.

La autotraducción es, en este sentido, otra forma de negociar contextos y límites literarios (Spoturno, 2019), en especial, en un proyecto nacionalizador como el de los románticos argentinos en general y Manso en particular.

Cabría agregar el hecho de que, como señala la historia cultural (McKenzie, 2005), el escritor no escribe libros sino textos, y que la publicación, por lo tanto, impone múltiples mediaciones y condiciones sobre su proyecto.

De este modo, el autotraductor no puede sustraerse al hecho de que es agente de una política lingüística, en la medida en que está señalando, tal vez más que el traductor de textos ajenos, cuáles son las segundas lenguas a las que hay que traducir los textos, cuáles las equivalencias entre variedades, cuáles las relaciones entre lenguas, culturas y naciones. Por eso, nos interesa aplicar a la autotraducción el concepto glotopolítico de representaciones sociales de las lenguas, que, desde la sociología del lenguaje, Roberto Bein (2008) define como

[...] los esquemas orientadores socialmente compartidos de la percepción y evaluación de los distintos fenómenos lingüísticos, que constituyen al mismo tiempo diseños más o menos complejos del universo social que los discursos sobre el lenguaje construyen, aunque hablen solo del lenguaje (p. 29).

Se expresan como discursos ("el italiano es musical", "el alemán es complejo", "las lenguas indígenas no sirven para la ciencia", etc.), que a su vez reflejan valoraciones ideológicas de los hablantes de esas lenguas y coinciden en lo que es lo correcto, lo ético, lo puro, lo elegante, lo nacional, lo progresivo, etc., en el lenguaje.

Estudiar a Juana Manso como autotraductora nos lleva a la necesidad de analizar sus prácticas de escritura en cada caso, dentro de sus condiciones concretas, puesto que con relación a la representación del español rioplatense como inferior al académico ( $\mathrm{y}$ al portugués brasileño como inferior al ibérico), plantearse las lenguas de gran área como pluricéntricas sería un asunto anacrónico: en el siglo XIX argentino, a excepción de los acotados proyectos periodísticos románticos, las traducciones y la mayoría de las producciones escritas se regían por el español académico peninsular. Manso impone, en cambio, la consideración de su peculiar situación de exiliada retornada, de mujer comprometida con la vida política y de transculturadora oscilante entre la innovación literaria y una concepción pedagógica y nacionalizadora de la literatura.

\section{Los misterios del Plata}

En 1852, durante su exilio en Río de Janeiro, Juana Manso publicó su primera novela en las páginas del periódico O Jornal das Senhoras, que ella misma dirigía y redactaba. Os Mysterios del Plata, en folletín, pretendía denunciar, para los lectores brasileños, "as atrocidades de [Juan Manuel de] Rosas, e os sofrimentos das suas víctimas" (1852, p. 6). Para ello, el terror europeo, que constituyó durante la primera mitad del siglo XIX un consumo literario exitoso entre los lectores americanos, brindó un lenguaje oportuno (Gasparini, 2014).

Manso fue, desde su niñez, una entusiasta consumidora de novelas y una activa participante de la sociabilidad literaria romántica, organizada entre Buenos Aires y Montevideo durante el segundo cuarto del siglo XIX. En las cartas que envió a Sarmiento, publicadas durante la década de los sesenta de ese siglo en los Anales de Educación Común, manifestó su reticencia a las lecturas escolares y su preferencia por las novelas francesas que circulaban ampliamente entre el escaso lectorado de la época.

Siendo adolescente, tradujo y publicó, con ayuda de su padre, dos novelas francesas, $E l$ egoísmo o la amistad y Mavrogenia o la heroína de Grecia (Velasco y Arias, 1937, p. 243). En estas 
lecturas y reescrituras, Manso aprendió los códigos del gótico y lo sentimental, de los que tomó las tramas maniqueas, los efectos melodramáticos, los usos del suspenso y las estructuras de personajes que dieron forma a su primera novela original. Los villanos del gótico, tiránicos y poderosos, empecinados en perseguir y torturar a una pareja de jóvenes y virtuosos amantes, ofrecieron un eficaz molde narrativo para representar a Rosas (1793-1877), su sistema y sus seguidores.

La escritora llegó a Río de Janeiro en 1843, luego de que el Sitio Grande de Montevideo obligara a su familia a abandonar la ciudad. Es su segundo exilio, ya que la participación de su padre en el Gobierno de Bernardino Rivadavia había hecho de la Buenos Aires rosista un destino inaccesible. Manso permaneció en Brasil hasta 1852 y allí se casó en 1847 con el músico portugués Francisco Sá Noronha, a quien acompañó en giras fallidas por Estados Unidos y Cuba, y con quien tuvo a sus dos hijas (Velasco y Arias, 1937).

Durante los largos años de exilio, Manso no abandonó los emprendimientos intelectuales: publicó poemas en la prensa, ofreció clases particulares, colaboró con su marido en la composición de piezas teatrales y, como ya señalamos, tradujo. Había aprendido el francés durante su infancia, como lengua de formación de las familias ilustradas, y el portugués y el inglés en el destierro.

E1 año 1853 fue una bisagra para la escritora, pues se concatenaron la caída de Rosas, la muerte de su padre y el posterior abandono del marido, por lo que regresó a Buenos Aires sin apoyo material alguno y a cargo de sus hijas. Al año siguiente, publicó el semanario Álbum de Señoritas. Con el periódico, buscaba compartir sus ideas sobre la emancipación femenina y obtener un ingreso que le permitiera mantenerse. La publicación, sin embargo, se interrumpió a los dos meses, por falta de suscriptoras.
Muchos motivos pueden explicar el fracaso del semanario: las polémicas prerrogativas autorales y editoriales de Manso (Batticuore, 2005), sus numerosas diatribas feministas que discutían con organizaciones como la Sociedad de Beneficencia, el escaso atractivo gráfico y tipográfico del diario, la falta de colaboradoras, la escasez general de lectorado. Una de ellas seguramente sea la renuncia que hizo la publicista a la traducción literaria, consumo favorito de los lectores decimonónicos porteños: "El elemento americano dominará exclusivamente los artículos literarios. Dejaremos la Europa" (1854, p. 1). En efecto, en el Álbum de Señoritas, Manso publicó traducciones de textos pedagógicos norteamericanos y su primera novela en español, La familia del comendador. Dicha renuncia a la traducción literaria amerita una reflexión en torno a la publicación de Guerras civiles en el Río de la Plata.

Quince años después de la primera aparición de la novela, Manso volvió sobre su decisión de no traducir literatura y volcó Os Mysterios del Plata al español para publicarlos por entregas entre el 29 de diciembre y el 16 de marzo de 1867, en las páginas de El Inválido Argentino, esta vez bajo el seudónimo de "Violeta". Esta versión del texto fue recuperada por la minuciosa biografía de la escritora, publicada por María Velasco y Arias (1937). Como la publicación en el periódico se interrumpió rápidamente, el texto se difundió de forma parcial. Esto hace que no podamos rastrear las transformaciones efectuadas sobre ciertos aspectos argumentales. En contra de lo que anuncia el subtítulo, el protagonismo de la esposa, que se desarrolla hacia las últimas entregas de la novela, es uno de ellos.

La edición completa en castellano que circula hoy, con el nombre Los misterios del Plata, fue elaborada a principios del siglo xx. Como ha analizado en profundidad Graciela Batticuore (2005), el editor del texto reescribió el final basado en la versión brasileña, por lo que el destino de Adelaida se desarrolla como en 
Os Mysterios del Plata, sin que podamos saber si esa habría sido la decisión tomada por la escritora.

En el contexto de 1867, cuando los románticos se encontraban en el bando vencedor y debían fundar la nación, Manso tradujo su novela sobre Rosas, lo que ilumina una serie de determinaciones y reconfiguraciones autorales que se juegan en la autotraducción. No solo los títulos y la firma modifican esta nueva edición, sino también las estrategias textuales implementadas en la traducción. El lector implícito del relato se actualiza, así como el nuevo contexto político, y la posición que Manso ocupa en él. Todo ello impone determinaciones que rastreamos en las transformaciones que realiza la reescritura autotraductiva.

\subsection{Os Mysterios del Plata y la importación del gótico}

Os Mysterios del Plata se publicó en una ciudad con una activa vida cultural, protagonizada por lectores familiarizados con el folletín francés (Abreu, 2009, 2012). Entre los diversos sueltos, semanarios y gacetines que circulaban por Río de Janeiro, había diarios financiados por Rosas, cuyo principal objetivo era el de construir una imagen favorable del gobernador. En 1847, el general Tomás Guido, ministro de Guerra y Relaciones Exteriores, inició también en Brasil O Americano, cuyas cuatro páginas reproducían noticias de la prensa porteña y europea a favor de Rosas (Weinberg, 2000).

Con esta novela, Manso se posicionó sobre un doble frente: por un lado, el de la ficción, donde sus Mysterios debían competir con un nutrido conjunto de novelas; por otro, el de la política, donde el folletín se vuelve un arma militante. Asimismo, esta apuesta polémica se desplegó en un periódico destinado al público femenino, que incluía figurines de moda, crónicas teatrales y partituras, lo que asociaba el seminario a la prensa frívola para mujeres, de creciente popularidad en América a mediados de siglo (Goldgel, 2013).

Ya desde su título, la novela de Manso establece una relación explícita con el folletín francés más exitoso de la época, Los misterios de París de Eugéne Sue. En Río de Janeiro, el primer folletín de Sue, volcado al portugués como Uma revolta no tempo do Império, había aparecido en 1841. La publicación, a cargo de O Diario, de Os Misterios de Paris y O Judeu Errante entre 1844 y 1845, marcó la consagración definitiva del autor en la ciudad.

Con el éxito popular de Sue en el meridiano de Greenwich literario (Casanova, 2021), el sintagma "misterios de" alimentó el imaginario de escritores de todo el globo, que se apropiaron de él con entusiasmo, dando lugar a misterios de Londres, de Buenos Aires y a literatura de cordel (Schapochnik, 2015). Sin embargo, la primera frase del prólogo escrito por Manso reniega inmediatamente de dicha filiación y decepciona la expectativa de lectura folletinesca: "Não foi por servil imitação aos mysterios de Paris, e aos de Londres, que chamei a este romance Mysterios del Plata” (1852, p. 6). ¿Cuál es, entonces, la intención de la autora, la clave genérica desde la cual propone a sus lectoras la novela?

Según sus palabras, su texto quiere revelar al mundo civilizado la barbarie del rosismo. "Chamei-o assim porque considero que as atrocidades de Rosas, e os sofrimentos das suas vítimas, serão um mysterio [sic] para as gerações vindouras, apesar de tudo quanto contra ele se tem escrito" (1852, p. 6). El misterio no es el de la intriga de los oscuros bajo fondos parisinos, sino el de la historia nacional. Se trata de un uso político de la ficción, que intenta conciliar la eficacia narrativa de la novela con el compromiso de la escritura periodística, por medio del cual Manso se establece como una mediadora cultural entre la situación argentina y los lectores brasileños. 
El gesto paradójico de apropiación y rechazo de la novela europea anunciado en el prólogo atraviesa todo el texto. Los misterios del Plata dialoga intensamente con la literatura gótica; sin embargo, dichas relaciones intertextuales no se explicitan como alusiones o citas, sino que deben ser rastreadas en la construcción de tramas, personajes y escenarios. En este sentido, las novelas góticas de Ann Radcliffe, célebres entre lectores y críticos a nivel mundial (Punter, 2014), debieron resultar poderosamente atractivas para una escritora que intentaba forjar su autoría en la compleja red de relaciones intelectuales masculinas de mediados de siglo.

Por otro lado, como señala Fred Botting (2005), las ficciones de Radcliffe no presentan los desbordes pasionales ni las resoluciones sobrenaturales de otros textos góticos (como El monje de Lewis o La religiosa de Diderot), sino que se resolvían con la restitución de la heroína al núcleo familiar y la celebración de la tranquilidad doméstica. Así, como ocurre para otros escritores como Sarmiento, José Mármol o Juana Manuela Gorriti (Ansolabehere, 2011; Gasparini, 2014), el gótico constituye una matriz altamente productiva para un texto cuyo objetivo era representar el terror rosista.

La historia cuenta el drama de la familia Avellaneda, la cual, al intentar exiliarse, es vendida a Rosas por Oribe. La embarcación en la que escapan es interceptada, y el doctor, encarcelado en Buenos Aires y condenado a muerte. La figura del villano gótico, de pasiones desmedidas y violencia tiránica, es el modelo narrativo desde el cual se da cuenta de Rosas y Oribe, personajes demoníacos, con un pasado oscuro quelos persigue y una mirada atemorizante, como la del célebre Schedoni de Radcliffe (Punter, 2014).

La prosa apacible y pintoresquista que abre el texto se abarrota ante la representación de Rosas:

Misterios negros como el abismo, casi increíbles en esta época y que es necesario que aparezcan a la luz de la verdad para que el crimen no pueda llevar por más tiempo la máscara de la virtud; para que, los verdugos y las víctimas sean conocidos y el hombre tigre - conocido hoy con el nombre de Juan Manuel de Rosas- ocupe su verdadero puesto en la historia contemporánea; el de un tirano atroz y sanguinario tan hipócrita como infame (Manso, 2006, p. 7).

El arsenal de lo que José Amícola (2003) define como una "escritura del exceso" se pone aquí al servicio de la representación del rosismo, cuyos procedimientos despóticos se comparan, al igual que en el gótico europeo, con la Inquisición. E1 texto recurre también a los paisajes tenebrosos propios del género: luego de su detención, Avellaneda es tenido prisionero, durante una noche tormentosa, en unas ruinas jesuíticas:

[...] a deserta Igreja conventual era só habitada pelas fatídicas corujas, e que os seus largos aposentos estavam solitarios, pavorosos, como as sepulturas dos outros enterrados debaixo das brancas e frias lages do seu pavimento (1852, p. 8).

En este escenario, cargado por la electricidad y los bramidos del yaguareté, se desarrolla el juicio al doctor. El paisaje argentino ingresa a la literatura como un espacio novelesco, escenario de una trama persecutoria donde los héroes virtuosos son acosados por delincuentes, cadenas, interrogatorios falsos y trampas. La familia unitaria se recorta de esta tétrica escena, los tres juntos rezan y el padre prodiga a su hijo unas palabras finales que reúnen la tópica del discurso liberal, basado sobre el trabajo, la familia y la fraternidad de los hombres.

El juicio es arbitrario, el acusado solo declara su nombre, edad y nacionalidad. La perversión del sistema queda explícita en el campo semántico con el que se representa la legalidad del régimen, el de la criminalidad. El interrogatorio toma así el cariz de un ritual satánico (el juez de paz es preso del "furor", gesticula diabólicamente) y de una representación en 
la que se repiten fórmulas preestablecidas y en la que la culpabilidad queda anunciada desde las primeras palabras del jurado. La escena reescribe los juicios inquisitoriales de las novelas de Radcliffe, tópico que Manso lee con atención para invertir los valores sobre los cuales se legitimó el Gobierno del "Restaurador de las leyes", que es en realidad un tirano, bajo el régimen de quien no hay ley más que la disposición personal y donde la institución familiar se desintegra.

Avellaneda no es asesinado, porque el gobernador lo quiere vivo. El juicio se clausura rápidamente y el doctor queda encadenado. La primera parte del folletín se cierra en el registro del melodrama, cuando Avellaneda es embarcado a Buenos Aires y su mujer y su hijo se lanzan al río para alcanzarlo y casi se ahogan.

Hay un aspecto en el que la novela se aleja del modelo gótico. Si bien, al igual que en el terror europeo, se reivindica el modelo romántico del amor consentido (el doctor aconseja a su hijo que si algún día se casa, ame a su mujer como él ama a la suya), se liman las controversias de un amor rebelde, no legitimado por la institución matrimonial, como el que era habitual en las ficciones europeas. Esto se debe a que el principal punto de ruptura en esta novela respecto de sus modelos europeos es la configuración de la heroína: virtuosa, pero no bella.

El modelo de la mujer refinada y melancólica que sufre desmayos constantes como la Clarisa de Samuel Richardson, sobre la cual se inspira Radcliffe para construir sus protagonistas femeninas (Watt, 1959), no tiene resonancias en Adelaida, mujer resuelta, activa y astuta. Disputando la representación del sentimentalismo femenino propio de la época (Batticuore, 2005), ella sabe disimular sus pasiones. Así, la novela de Manso invierte la representación genérica de la literatura gótica: es el personaje femenino quien adquiere un poder por sobre el masculino, pasivo e impedido de accionar por las cadenas y la cárcel (Gasparini, 2014).

\subsection{El inválido argentino: Manso, la autotraducción y la prensa}

La autotraducción de Manso se publicó como folletín en Buenos Aires en El Inválido Argentino, entre 1867 e inicios de 1868 , cuando se clausuró la publicación. Esta vez se tituló Guerras civiles del Río de la Plata. Primera parte. Una mujer heroica (en adelante, Guerras civiles en el Río de la Plata) y Manso la firmó con el seudónimo "Violeta".

El Inválido Argentino debe su peculiar nombre y sus pocos meses de duración a su naturaleza coyuntural. Dirigido por Juan María Gutiérrez, con el financiamiento de la familia del por entonces presidente Bartolomé $\mathrm{Mi}$ tre, el periódico se proponía recaudar fondos para el establecimiento de un hospicio de inválidos, dedicado a asistir a los soldados lisiados de la guerra del Paraguay, que el mismo Mitre había iniciado. Del comité de redacción también participaba José Mármol, amigo íntimo de Manso, a la que, en 1859, le había presentado a Sarmiento. Este encuentro implicó un giro afortunado para la escritora, desde entonces una activa colaboradora del proyecto educativo y político del autor de Facundo, quien, cuando asumió la presidencia, la nombró directora de la primera escuela normal mixta y, más tarde, miembro de la Comisión Nacional de Escuelas.

En esta época de su vida, la actividad de Manso se multiplica y diversifica. Desde 1865 , estuvo a cargo de la revista Anales de la Educación Común y de la fundación de la primera biblioteca popular, instalada en 1866 en la ciudad de Chivilcoy. Luego del ostracismo con que la sociedad porteña de 1854 había sancionado las pretensiones de Manso, "redactora y propietaria" del Álbum de Señoritas, la escritora en 1867 ostentaba otra posición y estrategias: como colaboradora reconocida de los románticos, mitigó su autoría bajo el seudónimo y a 
través de la reescritura autotraductiva moderó los desbordes del gótico y los recondujo al modelo de la novela nacional, moralizante y patriótica.

Desde estas labores, la escritora fue una fuerte defensora de la educación femenina y la democratización de la lectura a través de la novela. Para Manso, la publicación de Guerras civiles en el Río de la Plata constituyó una participación en un periódico caritativo, promovido y financiado por el mitrismo. La restricción y la oportunidad de esta autotraducción radicaban pues en su posibilidad de insertarse en una red de publicaciones sustentada por la sociabilidad patricia, sobre la que podía sostener su economía personal y negociar su proyecto pedagógico y feminista. Aseguradas las condiciones materiales de la publicación y las redes simbólicas prestigiosas, Manso apuesta, sobre todo, a construir una figura autoral de escritora nacional.

\subsection{Traducir. Domesticar la autoría y la novela para narrar la nación}

La publicación de la novela en El Inválido Argentino imprime numerosas modificaciones sobre la edición en portugués de 1852. La mayoría opera sobre lo que Jean-Michel Adam (2004) llama la "genericidad" del texto, y manifiesta la voluntad de Manso de hacer de su novela gótica sobre Rosas un modelo de la novela histórica nacional, como la promovían los románticos locales. Como sostiene Narvaja de Arnoux (2006):

En El Inválido Argentino, muchos años después, la lección que propone pertenece al campo de la moral política, propia del ejercicio de la democracia, que se asienta en la memoria del pasado, la historia en su valoración tradicional de maestra de la vida. Su posición ha variado, ya no es más la exiliada que "no tenía esperanzas de volver a la patria" (3), sino la colaboradora del futuro presidente. El discurso adopta, así, un tono estatal (p. 9).
Las transformaciones debidas a esta nueva posición se ven, en primer lugar, en los paratextos. De Los misterios del Plata y su referencia explícita a la novela francesa más exitosa de mediados de siglo, a Guerras civiles en el Río de la Plata, título que cancela toda expectativa folletinesca e inscribe el conflicto narrativo en la historia, Manso implementa una política de traducción nacionalizadora, que se reitera en numerosas zonas y niveles del texto. Ademásdecambiarlostítulos, laescritoraredactó dos introducciones diferentes. En la versión traducida, incluyó un "panorama político" que, al modo de las novelas históricas de Walter Scott, trazaba los acontecimientos públicos que enmarcaban el relato.

La introducción de la novela en portugués, a la vez que reniega de las influencias extranjeras, se abre en el registro desbordante y oscuro del gótico. Apenas menciona a Rosas, la prosa se abarrota: "Levantar o véu funerário de nosso passado, custa-nos muito, porque d'entre esse mar escarlate do mais puro sangue argentino, vemos levantar-se pálidos e medonhos os espectros de nossos amigos, de nossos irmãos" (1852, p. 7). Ante este tétrico diagnóstico, Manso sostiene que no hay que caer en un "cosmopolitismo indiferente", sino, como hemos mencionado, denunciar al mundo las barbaries del rosismo. Así, "sufriente", "nas agonias do amor pátrio", arrastrada a una "saudade tão duradoura como a existência" (1852, p. 7), Manso escribe lo que en la introducción denomina una y otra vez "romance":

Neste romance encontrareis talvez o que ainda se chamam "ideias muito livres" porque, apesar da sua civilização, o século 19 conserva preconceito e horrores, e mesmo frente a frente com a verdade, custa-lhe salir do gothico [sic] edifício (1852, p. 7).

De este modo, se hace presente el ethos autoral (Spoturno, 2019) en este prólogo: desde el desborde sentimental, desde la inspiración desgarrada por su patria lejana, Manso se construye a sí misma como una escritora, una literata 
cuya regla de composición le viene dada por la inspiración y el arrebato emocional, y que, en la justificación que intenta rendir al pudor femenino impuesto en la época (Batticuore, 2005), enuncia una clave genérica foránea para sus misterios: era el gótico, con su representación sanguinaria del pasado y sus espacios laberínticos y heterotópicos como configuración del poder tiránico (Noguera, 2017; Punter, 2014), el tipo de discurso literario que permitía a la joven escritora nostálgica de la patria representar la historia de su país.

El cambio en la retórica es patente en la nota introductoria que Manso dirige a sus lectores desde las páginas de El inválido argentino:

El romance histórico de nuestras guerras civiles tiene personajes reales que han sufrido y actuado en ellas; los colores locales y los accesorios del cuadro son del dominio de la fantasía del pintor que unas veces copia de la naturaleza y otras crea, inspirándose en el corazón (1937, p. 377).

Con esta breve frase, Manso interviene sobre la genericidad del texto. Guerras civiles en el Río de la Plata se inscribe en 1867 en el romance histórico y se excusa en el tópico biográfico de la obra de juventud. Contra los procedimientos del folletín extranjero, la escritora pone en primer plano la referencialidad del relato y el color local. Ante este nuevo pacto de lectura, aparece otro ethos:

[...] no es mi ánimo reanimar la llama de extintos rencores, ni alimentar la persistencia de odios acerbos de partido, pero la historia íntima de los hechos familiares debe no solo salvarse del olvido, sino utilizarse como lección provechosa de lo que importa el despojo de las libertades públicas y de los derechos individuales (1937, p. 378).

Esta cita condensa una serie de aspectos que marcan y determinan la autotraducción de la escritora. En el prólogo dirigido a los pocos lectores de El inválido argentino, Manso se desentiende de la escritura facciosa que definía la versión brasileña. Busca presentar, en cambio, una novela didáctica, con una tesis clara, que se pretende fundamentar y explicar a través del relato de la captura de un unitario (los daños de la tiranía sobre la domesticidad privada y la familia, soportes para el modelo liberal de Manso, Mitre y Sarmiento de la estabilidad nacional).

Dicha concepción didáctica y moralizante de la novela no es exclusiva de Manso, sino que forma parte de la poética del género que los románticos porteños habían cultivado y defendido desde mediados de siglo. Vicente Fidel López, en su Curso de Bellas Letras, ${ }^{3}$ definía a la novela como: "la idealización de un suceso doméstico, narrado con tono sencillo y vulgar, para interesar la imaginación, promover afectos morales y fortalecer los buenos principios de nuestra conducta privada" (1845, p. 297). La novela moral era aquella que, al ennoblecer la vida doméstica y sus afectos, "da impulso a simpatías para purificar las conductas" (p. 296).

La eficacia novelesca radicaba, para estos escritores, en su capacidad de inclinar la sensibilidad hacia la vida en sociedad y, en especial, en familia. Es decir, mostraba lo que quedaba fuera de la historia "oficial" (concebida como el relato de la vida pública de los grandes líderes y militares) y permitía la representación de otros personajes ajenos a ella, pero que la política pretendía representar (como las mujeres, los niños o los criados). La buena novela era la que podía mantener la vivacidad lectora, sin caer en las referencias adúlteras, banales o

3 En Chile, López fue contratado por la Facultad de Humanidades de la Universidad de Chile para ocupar la cátedra de Gramática, vacante desde el deceso de Andrés Bello. Como fruto de esta experiencia, publicó, en 1845, el Curso de Bellas Letras. Elvira Narvaja de Arnoux (2008) integra este trabajo a las artes de escribir ilustradas: manuales que buscaban enseñar a un lector no letrado los usos correctos de las lenguas vernáculas europeas (en este caso, el español) como lenguas nacionales, es decir, definiendo las reglas y formas correctas de los discursos públicos. 
lúbricas de las ficciones góticas; es decir, la que idealizaba en pos de modelar las conductas privadas de lectores y lectoras.

Como modelo literario, Fidel López (1845) reivindicaba, contra la influencia perniciosa de las novelas francesas, a Walter Scott. De este modo, Manso se inscribe en la normativa del género afirmada por los románticos porteños, filiación sobre la que insiste con la inclusión del segundo paratexto, el "panorama político", suerte de reseña histórica sobre el siglo XIX argentino, que no solo ancla el relato al contexto nacional, sino que también implica un procedimiento característico de la novela histórica escocesa, referente propuesto por Fidel López (1845, p. 301) como antídoto contra las novelas góticas y melodramáticas que Manso había consumido e incorporado a la escritura de Los misterios del Plata.

Asimismo, al introducir "El panorama político", Manso lo denomina "ojeada retrospectiva", citando el célebre ensayo homónimo de Esteban Echeverría. El paratexto repone la genealogía característica de la versión liberal de la historia argentina, que los mismos Echeverría, Sarmiento, Mitre y López fundaron (Donghi, 2005; Myers, 2003).

Se inicia con el conflicto entre unitarios y federales, donde Juan Lavalle es un santo traicionado por el "hipócrita" (Manso, 1937, p. 377) de Rosas. Viene luego el exilio unitario (que es el del padre de Manso) y, años más tarde, como consecuencia de la comprometida labor poética e intelectual de los jóvenes Echeverría y Alberdi, el exilio romántico y la desgracia del bloqueo francés (para el romanticismo, el más claro representante de la reticencia bárbara ante los beneficios civilizadores de Europa). Concluye el texto: "Esto era una algarabía de mueras y vivas de borracheras y orgías" (p. 377), representación del rosismo afín a la de Echeverría en La cautiva y a Sarmiento en Facundo (Piglia, 1986).
La organización de los capítulos y sus nombres varían en el mismo sentido. En el texto en portugués, el primer capítulo se llama " $O$ mensageiro", lo que inicia la novela en la lógica del misterio y la acción del folletín, a través un personaje anónimo, guardián de un mensaje secreto que incita la curiosidad del lector. Este procedimiento constituía un lugar común de la novela popular europea, característico de la dosificación del suspenso que implicaba la publicación por entregas. En la versión castellana, con el subtítulo "La estancia", la referencia se nacionaliza.

Antes de narrar, Manso sitúa la acción en un paisaje nacional fuertemente signado por el color local y el pintoresquismo, aquel que habían utilizado para construir sus novelas escritores como Mitre y Gutiérrez. ${ }^{4}$ El segundo capítulo también sufre una modificación y pasa de "Miguel" a "El gaucho Miguel": a la voluntad patente de describir el paisaje argentino, se suma la presentación de sus personajes tipo, gauchos malos, cantores y baqueanos ausentes en el texto en portugués, y configurados en Facundo. Esta misma transformación, que descarta la lógica folletinesca por la domesticación, se da en otros subtítulos como "Lágrimas"/ "Los leñadores del Paraná" o "Dois malvados" / "El cafecito de San Juan".

Las descripciones de los paisajes son una de las zonas del texto donde operan mayor cantidad de estrategias aclimatadoras y transformadoras. La traducción asume aquí la forma del parafraseo estilístico, que si bien mantiene determinados ítems léxicos que sedimentaban en

\footnotetext{
$4 \mathrm{El}$ paisaje pampeano, concebido a la vez como desierto y patrimonio, es tópico, ideal y problema de la poética del romanticismo argentino. Con descripciones de este espacio se inician "La cautiva" y "El matadero", los textos fundacionales de Echeverría (Rodríguez, 2019). Asimismo, esta misma preocupación por la descripción del paisaje americano puede rastrearse en otras novelas del romanticismo argentino como El capitán de Patricios de Juan María Gutiérrez y Soledad de Bartolomé Mitre.
} 
la época la tópica del paisaje nacional, como el ombú o la llanura, altera y alarga la sintaxis de la frase, le intercala subordinadas y adjetivos, detalla descripciones, descarta aspectos indecorosos. Si, en la versión brasileña, el paisaje argentino ingresaba como un espacio novelesco y macabro, como el convento en ruinas plagado de alimañas en el que se juzgaba a Avellaneda, Guerras civiles en el Río de la Plata apela a la sosegada pampa del ombú y la producción agrícola.

Así, la novela se vuelve más extensa, pero no por la arborización de conflictos y personajes que caracterizaba a las ficciones góticas, sino por la incorporación de descripciones y elementos costumbristas (como décimas de amor gauchas) que refuerzan el locus del texto y redundan en una versión significativamente más extensa que la publicada en $O$ Jornal das Senhoras. La prosa se despeja, gana fluidez y claridad, pero pierde patetismo.

Esta atenuación estilística opera igualmente a nivel político. Luego de la batalla de Caseros, como sostiene la misma Manso en la introducción a Guerras civiles en el Río de la Plata, es necesario limar posibles asperezas que recuerden el conflicto social reciente, todavía vívido en la sociedad porteña. Con este fin, el imaginario novelesco se modera para dar lugar a las alusiones republicanas. La barcaza en la que huye la familia Avellaneda de la mazorca se llamaba, en el folletín brasilero, "Francesca Di Rimini", alusión a la lectora de novelas adúltera que aparece en Divina Comedia de Dante. En la traducción al español, la balandra se denomina "Constitución": la autotraducción de Manso es una reformulación y una celebración del texto sobre el que se funda el Estado liberal moderno y nacionalista. En el mismo sentido operan las reformulaciones en torno al gaucho Miguel, que ha estudiado con detenimiento Narvaja de Arnoux (2006): en Guerras civiles, se borran las alusiones a los orígenes espurios del muchacho y se desarrolla y enaltece su carácter de buen peón.
Por otro lado, las pocas estrategias de reducción rastreadas también operan en este sentido. Ciertas explicaciones innecesarias para el público argentino, como la procedencia del término "unitario", se eliminan; desaparecen, asimismo, numerosas expresiones dramáticas del narrador sobre el destino de los protagonistas y sus alusiones despectivas al bajo pueblo violento. Las supresiones igualmente acentúan la intención didáctica de la novela: "Los Misterios del Plata va a ofrecer con los hechos históricos y leales un amplio conocimiento de esos países" (Manso, 2006, p. 9).

Con tales estrategias, el protagonismo se corre, como lo indica el nuevo título, a la protagonista femenina. Las ficciones góticas, protagonizadas y escritas por mujeres, le abrieron a Manso no solo un espacio para intervenir en la polémica rosista, sino también uno desde el cual criticar la subordinación social de la mujer en el Río de la Plata. Sin embargo, en las sucesivas reescrituras y traducciones de la novela, el registro pasional se atenuó, la prosa se purgó y se esterilizó, y el ethos folletinesco se volvió explicativo y austero.

\section{Conclusiones}

Las estrategias desplegadas por Juana Manso en su autotraducción de Los misterios del Plata construyen una nueva genericidad para el relato, que se distancia del gótico para inscribirse en el modelo de novela histórica nacional, como la poetizaban los románticos porteños, en cuyos proyectos periodísticos y estatales Manso se insertó como colaboradora asidua y entusiasta. Estos escritores defendieron un modelo de novela moral que, al igual que Guerras civiles en el Río de la Plata, buscaba producir en sus lectores el sentimiento de nacionalidad (cf. Anderson, 1993) a partir de la representación pintoresquista del paisaje nacional y la idealización de las costumbres domésticas. Esa concepción del género significó para la escritora una traducción ennoblecedora: en la versión en español, se domestica e intensifica el paisaje pampeano, las descripciones son 
más cuidadas, se atenúa el patetismo y la morbosidad, se anexan paratextos pedagógicos.

Las transformaciones operadas por la reescritura autotraductiva evidencian la voluntad de Manso de hacerse un nombre como autora de la novela nacional (Batticuore, 2005). Los numerosos procedimientos de atenuación y domesticación que realiza para la versión ofrecida por El Inválido Argentino señalan que Manso también quería ser reconocida como una escritora romántica, participar en los periódicos de sus pares, recibir su reconocimiento y escribir como ellos.

Veinte años después de la aparición de Los misterios del Plata en el exilio, la autotraducción no convocó una política literalista, norma dominante en la traducción decimonónica, sino una negociación de la genericidad que, al afiliarse a un modelo de novela local, reestructuró profundamente técnicas narrativas, estética y políticas.

\section{Referencias}

Abreu, M. (2009). Libros y libreros en Río de Janeiro (1808-1821). Floema, 3(5), 7-30.

Abreu, M. (2012). El gusto de los lectores. La recepción de novelas como problema para la historia literaria. Orbis Tertius, 17(18), 1-13. https:// www.orbistertius.unlp.edu.ar/article/view/ OTv17n18d03

Adam, J.-M. (2004). Des genres à la généricité. L'exemple des contes (Perrault et les Grimm). Langages, (153), 62-72.

Alberdi, J. B. (2011). La moda. Edición facsimilar. Biblioteca Nacional.

Amícola, J. (2003). La batalla de los géneros. Novela gótica versus novela de educación. Beatriz Viterbo.

Anderson, B. (1993). Comunidades imaginadas. Fondo de Cultura Económica.

Ansolabehere, P. (2011). Pampa gótica: el origen del terror en la literatura argentina. En N. Domínguez (comp) (pp. 11-17). Editorial de la Facultad de Filosofía y Letras.

AUTOTRAD (2007). L'autotraduction littéraire comme domaine de recherche. Atelier de Traduction, (7), 92-93. https://usv.ro/fisiere_utilizator/file/ atelierdetraduction/arhive/arhive_full_text/atelier_de_traduction_7.pdf

Batticuore, G. (2005). La mujer romántica. Lectoras, autoras y escritores en la Argentina: 1830-1870. Edhasa.

Bein, R. (2008). Aspectos sociolingüísticos de la autotraducción. En A. M. Granero (Comp.), La traducción. Hacia un encuentro de lenguas y culturas (pp. 21-30). Centro de Investigación en Traducción, Facultad de Lenguas, Universidad Nacional de Córdoba y Ed. Comunicarte.

Botting, F. (2005). Gothic. Routledge.

Brisset, A. (1990). Sociocritique de la traduction. Théâtre et altérité au Québec. Éditions du Préambule.

Carvalho Fonseca, L., Ramos da Silva, L., y Silva-Reis, D. (2020). Consideraciones fundamentales de los estudios de la traducción feminista en América Latina. Mutatis Mutandis. Revista Latinoamericana de Traducción, 13(2), 210-227. https://doi.org/10.17533/udea.mut.v13n2a01

Casanova, P. (2021). La lengua mundial. Traducción y dominación (Laura Fólica, Trad.). Ethos [orig.: $L a$ langue mondiale. Traduction et domination. Éditions $\mathrm{du}$ Seuil, 2015].

Dasilva, X. M. (2015). La opacidad de la autotraducción entre lenguas asimétricas. TRANS, 2(19), 171-182. https://doi. org/10.24310/TRANS.2015.v2i19.2070

Dasilva, X. M. (2018). La autotraducción opaca en la obra bilingüe de Carlos G. Reigosa. TRANS, (22), 223-235. https://doi.org/10.24310/ TRANS.2018.v0i22.4119

Donghi, T. H. (2005). Una nación para el desierto argentino. Prometeo Libros.

Fernández Speier, C. (2019). Las traducciones argentinas de la Divina Comedia. De Mitre a Borges. Eudeba. 
Fidel López, V. (1845). Curso de Bellas Letras. Imprenta del Siglo.

Gasparini, S. (2014). El terror como enfermedad. Facundo y las fascinaciones de la barbarie en Sarmiento y Gorriti. Badebec, 6, 169-185. http:// hdl.handle.net/2133/15552

Goldgel, V. (2013). Cuando lo nuevo conquistó América. Prensa, moda y literatura en el siglo XIX. Siglo XXI.

Grutman, R. (2009). La autotraducción en la galaxia de las lenguas. Quaderns: revista de traducció, (16), 123-134.

López López-Gay, P. (2008). La (auto)traducción literaria [Tesis doctoral]. Universitat Autònoma de Barcelona.

Manso, J. (1854) Álbum de Señoritas. Periódico de Literatura, Modas, Bellas Artes y Teatro. 8 entregas (10 de enero a 17 de febrero de 1854). https://drive.google.com/file/ d/0B5Xby9_ds9QYRDBiam5LUC11cGZ5X0 Z1QXhNMEljYzQzT19V/view?resourcekey=0gY5QrGXiDi5wVJBxXsXTGw

Manso, J. (1855) O Jornal das Senhoras. Modas, Litteratura, Bellas-Artes, Theatros e Critica (1852-1855). http://objdigital.bn.br/acervo_digital/div_periodicos/per700096/per700096_anuario.htm

Manso, J. (1868). Carta miscelánea. Anales de la Educación Común, (4), 216-220.

Manso, J. (1937). Guerras civiles del Río de la Plata. Primera parte. Una mujer heroica. En: M. Velasco y Arias, Juana Paula Manso. Vida y acción (pp. 376419). Porter Hermanos.

Manso, J. (2006). Los misterios del Plata. Buena Vista.

McKenzie, D. (2005). Bibliografia y sociología de los textos. (Fernando Bouza, Trad.). Akal Ediciones.

Myers, J. (2003). Aquí nadie vive de las bellas letras. Literatura e ideas desde el Salón Literario a la Organización Nacional. En N. Jitrik (Dir.), Historia crítica de la literatura argentina. La lucha de los lenguajes (Vol. 2, pp. 305-333). Emecé.
Narvaja de Arnoux, E. (2006). La representación del género y de los espacios de circulación del texto en las reescrituras de los misterios del Plata de Juana Manso. En Análisis del discurso. Modos de abordar materiales de archivo (pp. 95-130). Santiago Arcos.

Narvaja de Arnoux, E. (2008). Los discursos sobre la nación y el lenguaje en la formación del estado (Chile, 1842-1862). Estudio glotopolitico. Santiago Arcos.

Noguera, L. (2017). Teatro y frontera. Cruces y desplazamientos geográficos y culturales durante el romanticismo rioplatense (1837-1857). Eudeba.

Pagni, A. (2013). El lugar de la traducción en los proyectos editoriales argentinos en la segunda mitad del siglo xIx: El Plata Científico y Literario (1854-1855) y La Biblioteca Popular de Buenos Aires (1878-1883). En K. Carrillo Zeiter y M. Wehrheim (Eds.), Literatura de la Independencia, independencia de la literatura. (pp. 45-66). Vervuert, Iberoamericana.

Piglia, R. (1986). Crítica y ficción. Anagrama.

Punter, D. (2014). The Literature of terror. A history of Gothic Fictions from 1765 to the present day. Routledge.

Rodríguez, F. (2019). Un desierto para la nación: la escritura del vacío. Eterna Cadencia.

Schapochnik, N. (2015). Mysterymania: de Paris au Río de la Plata. En D. Kalifa y M.-E. Thérenty (Dirs.), Les Mystères urbains au XIX siècle: circulations, transferts, appropriations. Médias 19, 1-13. http://www.medias19.org/index.php?id=17039

Sperti, V. (2017). L'autotraduction littéraire : enjeux et problématiques. Revue italienne d'études françaises, (7). https://doi.org/10.4000/rief.1573

Spoturno, M. L. (2015). El problema de las variedades lingüísticas en la traducción al español de la literatura latina de Estados Unidos: el caso de Julia Álvarez y de Sandra Cisneros. Lenguas Vivas, (10), 18-29. https://ri.conicet.gov.ar/ handle/11336/7713 
Spoturno, M. L. (2019). El retrabajo del ethos en el discurso autotraducido. El caso de Rosario Ferré. Hermēneus, (21), 323-354. https://doi. org/10.24197/her.21.2019.323-354

Tanqueiro, H. (2002) Autotradução: Autoridade, privilégio e modelo [Tesis doctoral]. Universitat Autònoma de Barcelona.

Toury, G. (2005). La naturaleza y el papel de las normas en la traducción. En Los estudios descriptivos de traducción y más allá. Metodología de la investigación en estudios de traducción (pp. 94-107). Cátedra.

Velasco y Arias, M. (1937). Juana Paula Manso: vida y acción. Porter Hermanos.

Watt, I. (1959). The rise of the novel. Studies in Defoe, Richardson and Fielding. University of California Press.
Weinberg, F. (2000). Antecedentes y evolución del romanticismo argentino. Investigaciones y Ensayos, (50), 19-31.

Willson, P. (2008). El fin de una época: letrados-traductores en la primera colección de literatura traducida del siglo xx en la Argentina. TRANS. Revista de Traductología, (12), 29-42. https://doi. org/10.24310/TRANS.2008.v0i12.3126

Zucotti, P. (1994). Manso: de las Veladas literarias a "Las conferencias de maestra". En L. Fletcher (Comp.), Mujeres y cultura en la Argentina del siglo XIX (pp. 96-107). Ed. Feminaria.

Zucotti, P. (1995). Los misterios del Plata, el fracaso de una escritura pública. Revista Interamericana de Bibliografia, 45(3), 381-390.

Cómo citar este artículo: Vázquez, A. E. (2022). Factores que condicionan la autotraducción. El caso de Los misterios del Plata, de Juana Manso. Mutatis Mutandis. Revista Latinoamericana de Traducción, 15(1), 95-110. https://doi.org/10.17533/udea.mut.v15n1a06 